\title{
TRATAMENTO TÉRMICO DE PRECIPITAÇÃO - T6 APLICADO EM RODA DE LIGA LEVE DE MOTOCICLETA
}

\author{
R. O. M. OLIVEIRA ${ }^{1}$ e O. F. L. ROCHA ${ }^{2^{*}}$ \\ ${ }^{1}$ Instituto Federal de Educação, Ciência e Tecnologia do Pará - IFPA \\ ${ }^{2}$ Universidade Federal do Pará - UFPA \\ otvrocha@oi.com.br*
}

Artigo submetido em agosto/2014 e aceito em novembro/2014

DOI: 10.15628/holos.2014.2337

\section{RESUMO}

As ligas de alumínio da série A356 (Al-Si-Mg) são usadas extensivamente em componentes de manufatura para indústria automotiva e aeroespacial devido a suas propriedades físicas e mecânicas. São utilizadas em muitas aplicações estruturais que requerem uma alta resistência a baixo peso, alta resistência e tenacidade ao impacto, baixo coeficiente de expansão térmica, boa resistência à corrosão e excelente fluidez, como ligas de fundição para produção de rodas de liga leve. Nesse sentido, o objetivo principal deste trabalho é avaliar os efeitos do tratamento térmico de precipitação - T6 sobre a microestrutura e propriedades mecânicas da liga A356/Al-7Si-0,3Mg. Para tanto, uma roda de motocicleta foi utilizada e o tratamento térmico aplicado na própria indústria de fabricação, conforme padrões estabelecidos. Os resultados alcançados mostram uma microestrutura eutética composta de $\mathrm{Si}$ (esferoidizado) mais os intermetálicos de Fe, que foram observados entre as ramificações interdendríticas. Ensaios de dureza Rocwell B foram realizados e os valores obtidos correspondem aos padrões estabelecidos.

PALAVRAS-CHAVE: Solubilização, Envelhecimento, Microestrutura Dendrítica, Dureza, Ligas Al-Si-Mg.

\section{T6 - PRECIPITATION HEAT TREATMENT APPLIED IN LIGHT ALLOY WHEEL OF MOTORCYCLE}

\begin{abstract}
The aluminum alloy A356 (Al-Si-Mg) are used extensively in manufacturing components for automotive and aerospace industries due to their physical and mechanical properties. They are used in many structural applications requiring high strength at low weight, high strength and impact resistance, low coefficient of thermal expansion, good corrosion resistance and excellent fluidity, such as casting alloys for the production of light alloy wheels. In this sense, the main objective of this work is to evaluate the effects of T6-precipitation heat treatment on the
\end{abstract}

microstructure and mechanical properties of the A356 Al$7 \mathrm{SI}-0.3 \mathrm{Mg}$ alloy. To this end, a wheel of motorcycle has been used and the heat treatment administered in the manufacturing industry, as established standards. The results show a eutectic microstructure composed of $\mathrm{Si}$ (spherical silicon) and Fe intermetallic which has been observed between the dendritic ramifications. Rocwell B - hardness tests were carried out and the values correspond to the established standards.

KEYWORDS: Solubilization, Aging, Dendritic Microstructure, Hardness, Al-Mg-Si alloys. 


\section{INTRODUÇÃO}

Atualmente o alumínio desempenha um papel bastante importante na nossa sociedade e em todo o mundo, produz-se cerca de treze (13) vezes mais do que há 60 anos (Lima, 2012; Oliveira, 2012). Segundo Lima (2012) e Oliveira (2012) o alumínio aumenta ainda mais a sua versatilidade quando combinado com outros elementos para formarem ligas. A sua densidade, 2,7 $\mathrm{g} / \mathrm{cm}^{3}$, torna essas ligas particularmente atrativas para a utilização em transportes, tornando as estruturas dos diferentes meios de transporte mais leves e eficazes, em comparação com os materiais previamente utilizados.

Muitos elementos metálicos podem ser combinados com o alumínio para formar as suas ligas, sendo os mais utilizados: cobre, magnésio, manganês, silício e o zinco. Em função do produto, as ligas de alumínio podem ser classificadas como ligas de deformação plástica ou de fundição. Dentro destas categorias as ligas são agrupadas em séries de acordo com os elementos de liga principais (Moreira, 2011; Furlan, 2008).

A facilidade que o alumínio apresenta de se combinar com outros elementos aumenta o número de aplicações das suas ligas. Dentre esses, destaca-se o silício como um dos principais elementos, que é bastante útil na produção das ligas de alumínio em fundição. É responsável pela boa fluidez do metal em fusão, o que permite preencher todo o molde e, para teores superiores a $5 \%$, diminui a fissuração a quente. Com o aumento do teor em silício, o coeficiente de dilatação diminui. A solubilidade do silício no alumínio no estado sólido é reduzida, 1,65\%, formando um eutético com o alumínio para teores de $12,6 \%$. Sendo uma fase dura, o silício contribui para o aumento da resistência ao desgaste e, quando combinado com outros elementos, permite tornar as ligas tratáveis termicamente (Lima 2012, Garcia, 20017). Dependendo do teor de silício as ligas são classificadas como hipoeutéticas (abaixo 12,6\%), eutéticas (12,6\%) e hipereutéticas (acima de $12,6 \%)$.

As ligas Al-Si são, portanto, excelentes materiais para componentes estruturais da indústria automotiva e aeroespacial pela elevada relação resistência/peso. Devido, ainda, a excelente fluidez que essas ligas apresentam o que proporciona num ótimo preenchimento de moldes para fundição, permitindo a produção de peças de elevada complexidade dimensional, são selecionadas como material ideal à fabricação de rodas de ligas leves (Manente \& Tomelli, 2011). Apresentam também uma boa resistência à corrosão (Lima, 2012; Oliveira, 2012; Moreira, 2011, Furlan, 2008).

O eutético Al-Si pode ser modificado através da utilização de determinados elementos de liga com o objetivo de alterar a morfologia do silício de acicular para mais esférica, melhorando as propriedades mecânicas (Menente e Tomelli, 2011; Tash et al, 2007; Ozbakir, 2008; Gruzleski, 1990; Oullet \& Samuel, 1999; Kim et al, 2006; Wang et al, 2001; Zhen et al, 1997; Zhang, 1996; Closset \& Gruzleski, 1982). A adição de magnésio, por exemplo, nas ligas Al-Si permite endurecelas por tratamento térmico de precipitação. O magnésio combina-se com o silício e forma a fase $\mathrm{Mg}_{2} \mathrm{Si}$, a base para o endurecimento por precipitação e responsável pelo aumento da resistência mecânica destas ligas (Lima, 2012; Oliveira, 2012; Moreira, 2011, Furlan, 2008; Menente e Tomelli, 2011; Tash et al, 2007; Ozbakir, 2008; Gruzleski, 1990; Oullet \& Samuel, 1999; Kim et al, 2006; Wang et al, 2001; Zhen et al, 1997; Zhang, 1996; Closset \& Gruzleski, 1982). 
Na liga A356 os teores de silício e magnésio variam entre 6,5\% a 7,5\% e 0,25\% a 0,45\%, respectivamente. Neste trabalho, utiliza-se a composição Al-7\%Si-0,35\%Mg (\% em peso). Essa liga apresenta baixas quantidades de impureza e fases intermetálicas, além de excelente soldabilidade, resistência à corrosão, estanqueidade, ótima fundibilidade, elevada relação resistência/peso e baixo custo. O cobre e o ferro são impurezas que devem ser controladas, pois formam compostos intermetálicos que fragilizam o material.

Ozbakir (2008) considera o Fe a maior impureza em ligas Al-Si-Mg. Segundo o autor, níveis usuais de ferro variam de $0,1 \%$ a $1 \%$ para ligas primárias e secundárias, respectivamente. $\mathrm{O} F e$, com teor acima de $1 \%$, combinado com $\mathrm{Si}, \mathrm{Al}$, e $\mathrm{Mg}$ forma o mais comum dos intermetálicos $\beta$ $\mathrm{Al}_{5} \mathrm{FeSi}$. Kim et al (2006) mostraram em seus resultados, para a liga A356-T6, contendo um teor de Fe acima de $0,2 \%$, ligeiro aumento da resistência à deformação, com significativas reduções da resistência à tração e do alongamento. Wang et al (2001) observaram para teores de Fe cerca de 0,15\% (ligas primárias) e 0,48\% (ligas secundárias), menores valores de resistência à tração e de alongamento para a liga $\mathrm{A} 356 \mathrm{com}$ de $0,48 \% \mathrm{Fe}$. Neste trabalho, os teores de Cu e, principalmente, o de $\mathrm{Fe}$, foram controlados com teores máximos de $0,019 \%$ e $0,144 \%$, respectivamente.

Segundo (Furlan, 2008; Menente e Tomelli, 2011; Tash et al, 2007; Ozbakir, 2008) o tratamento térmico de precipitação - T6 compreende as seguintes etapas: solubilização, têmpera e envelhecimento artificial.

No tratamento de solubilização em ligas Al-Si-Mg ocorre a dissolução do $\mathrm{Mg}_{2} \mathrm{Si}$ na matriz $\alpha$ A e homogeneização da microestrutura com a eliminação da microssegregação interdendrítica. No caso de ligas de alumínio fundidas, a solubilização resulta em: 1) dissolução dos elementos de liga Si e Mg na matriz de alumínio, 2) dissociação da estrutura do silício e esferoidização das partículas resultantes e, 3) uma homogenização geral com eliminação da microssegregação (Moreira, 2011; Furlan, 2008).

A temperatura de solubilização tem uma forte influência na morfologia da partícula do Si. Engrossamento de partículas de Si podem ser obtidas em temperaturas maiores que $560^{\circ} \mathrm{C}$. Em trabalhos sobre ligas Al-Si-Mg, verificou-se que aumentando a temperatura de solubilização de 540 ${ }^{\circ} \mathrm{C}$ para $550{ }^{\circ} \mathrm{C}$ aumentam-se as propriedades de resistência (Shivkumar et al, 1990a; 1990b; 1990c).

Assim como a temperatura o tempo de solubilização influência significativamente na morfologia do Si e, consequentemente, nas propriedades mecânicas. A resistência à tração e o alongamento aumentam, por exemplo, com o tempo de solubilização (Moreira, 2011; Furlan, 2008). Por outro lado, a modificação do Si por tratamento químico aumenta a ductilidade, mas diminui a resistência à tração. Em geral, o efeito da modificação química é reduzir o tempo de solubilização visando qualidade (melhores propriedades) com produtividade. $O$ efeito do tempo de tratamento térmico de solubilização sobre a morfologia do Si utilizando um reator de leito fluidizado (alta taxa de aquecimento) e um forno convencional de resistência foi verificado por Chaudhury et al (2004). A liga utilizada foi A356 modificada por estrôncio (0,006\%Sr em peso), os autores conseguiram um excelente equilíbrio entres boas propriedades mecânicas com menores de tempo de solubilização que os recomendados pelos padrões técnicos.

$\mathrm{Na}$ indústria de fundição é normalmente especificado 6 horas de solubilização em $540{ }^{\circ} \mathrm{C}$ para a liga A356. Entretanto, Emadi et al (2003) têm sugerido um ótimo tratamento de solubilização para a liga A356 de somente $4 \mathrm{~h}$ em $540^{\circ} \mathrm{C}$. Por outro lado, Shivkumar et al (1990a, 
1990b, 1990c) demonstraram que para ligas A356 modificadas, fundidas em molde permanente, o tratamento de solubilização de 50 minutos foi suficiente para que o $\mathrm{Mg}$ e Si contido na matriz alcançasse nível de equilíbrio máximo de acordo com a composição da liga e suas distribuições se tornassem homogêneas. Esse tempo de solubilização, também foi suficiente para alcançar $90 \%$ do limite máximo de resistência da liga.

Segundo a literatura (Furlan, 2008; Menente e Tomelli, 2011; Tash et al, 2007; Ozbakir, 2008) o principal requerimento para a duração do tratamento térmico de solubilização, é de ser suficientemente longo para dissolver primeiramente as partículas de $\mathrm{Mg}_{2} \mathrm{Si}$ formadas durante a fundição, e permitir a difusão dos elementos dissolvidos dentro da matriz de alumínio. No entanto, modelos matemáticos desenvolvidos por Rometsch et al (1999) indicam que a dissolução do $\mathrm{Mg}_{2} \mathrm{Si}$ primário é completado dentro de menos do que uma (1) hora de tratamento de solubilização, isto é, segundo os autores a completa homogeneização do intermetálico $\mathrm{Mg}_{2} \mathrm{Si}$ na matriz rica em alumínio (Al- $\alpha$ ) acontece para um tempo de tratamento menor que uma (1) hora (Pedersen \& Arnberg, 2001). Os autores trabalharam com quatro (4) ligas AlSiMg fundidas, dentre elas a Al-7Si$0,2 \mathrm{Mg}$, composição muita próxima da liga estudada neste trabalho, encontraram uma alta resistência à tração depois de 60 minutos de solubilização, tanto para liga modificada como não modificada por $\mathrm{Sr}$, indicando que a solução sólida de alumínio (Al- $\alpha$ ) é rapidamente saturada de Mg e Si.

O objetivo da têmpera é preservar a solução sólida formada na temperatura de solubilização por resfriamento rápido a temperaturas próximas a do ambiente (Lima, 2012; Oliveira, 2012; Moreira, 2011; Furlan, 2008; Menente e Tomelli, 2011; Tash et al, 2007; Ozbakir, 2008). O meio de resfriamento rápido mais usado é a água, embora, caso seja necessária uma taxa de resfriamento mais baixa, podem ser usados diversos líquidos orgânicos como meios de resfriamento rápido, como salmora, óleo, soda caustica ( $5 \%$ a $10 \%)$ e solução de polímeros. No presente trabalho foi utilizada a água como meio de resfriamento.

O tratamento térmico de envelhecimento é o último passo no processo de endurecimento por precipitação e consiste na precipitação controlada do soluto para formar precipitados finamente disperso na matriz de $\alpha$-Al. Uma série de precipitações foram observadas neste processo, iniciando com a formação de agregados de átomos de magnésio e silício, designados de zonas de precipitação ou zonas Guinier-Preston (GP), que devido à sua instabilidade se decompõem rapidamente em fases metastáveis $(\beta$ ", $\beta$ ') e terminando com a formação da fase estável $\beta-\mathrm{Mg}_{2} \mathrm{Si}$, todo o processo pode ser observado pelo esquema da Figura 1 (Lima, 2012; Oliveira, 2012; Moreira, 2011; Furlan, 2008; Menente e Tomelli, 2011; Tash et al, 2007; Ozbakir, 2008).

\begin{tabular}{|c|c|c|c|}
\hline $\begin{array}{c}\text { Solução sólida } \\
\text { supersaturada (Alsss) }\end{array}$ & $\begin{array}{c}\text { Fases metaestáveis } \\
\text { (Si acicular) }\end{array}$ & $\begin{array}{c}\text { Precipitados em } \\
\left(\beta^{\prime \prime}, \beta^{\prime}\right) \quad\end{array}$ & $\begin{array}{r}\text { Fase } \beta-\mathrm{Mg}_{2} \mathrm{Si} \\
\text { (fase estável) }\end{array}$ \\
\hline
\end{tabular}

Figura 1. Esquema representativo da precipitação da fase $\beta-\mathrm{Mg}_{2} \mathrm{Si}$ durante o envelhecimento.

A sequência de precipitação apresentada na Figura 1 pode ser resumida da seguinte forma:

(a) Precipitação das zonas GP (agulhas de aproximadamente $10 \mathrm{~nm}$ de comprimento);

(b) Fase intermediária $\beta^{\prime \prime}-\mathrm{Mg}_{2} \mathrm{Si}$ (Precipitação homogênea); 
(c) Fase intermediária $\beta^{\prime}-\mathrm{Mg}_{2} \mathrm{Si}$ (Precipitação heterogênea);

(d) Fase de equilíbrio $\beta-\mathrm{Mg}_{2} \mathrm{Si}$.

Assim como no tratamento de solubilização, a temperatura e o tempo no processo de envelhecimento estão fortemente inter-relacionados e influenciam significativamente no processo de precipitação das fases. O tempo necessário para a formação das zonas GP é inversamente proporcional à temperatura de envelhecimento, ou seja, aumentando a temperatura de envelhecimento diminui o tempo necessário para a formação destas zonas (Furlan, 2008; Menente e Tomelli, 2011; Tash et al, 2007; Ozbakir, 2008).

A norma ASTM B-597 (Standard Practice for Heat Treatment of Aluminum Alloys, Annual Standard Book of ASTM Standards, B597, 1998) estabelece padrões para a liga A356-T6 de temperaturas e tempos para realização de tratamento térmico de precipitação. Essa norma recomenda temperaturas de $540{ }^{\circ} \mathrm{C}$ durante 4 a 12 horas, para solubilização e de $220^{\circ} \mathrm{C}$ durante 7 a 9 horas, para envelhecimento artificial. Na literatura (Furlan, 2008; Menente e Tomelli, 2011; Tash et al, 2007; Ozbakir, 2008), a mesma temperatura de solubilização é utilizada, mas as temperaturas de envelhecimento geralmente variam entre 185 a $240{ }^{\circ} \mathrm{C}$.

Considerando o exposto, este trabalho teve como objetivo principal avaliar os efeitos do tratamento térmico de precipitação - T6 sobre a microestrutura e dureza da liga Al-7Si-0,3Mg (A356-T6), utilizada como liga de fundição para produção de rodas de ligas leve de motocicleta . 0 tratamento térmico T6 foi aplicado na indústria de fabricação da motocicleta, obedecendo a padrões estabelecidos. Vale destacar que este estudo é o início de outros mais abrangentes que se encontra em desenvolvimento pelos autores deste trabalho, cujo foco é otimizar o tratamento térmico T6, reduzindo o tempo de solubilização, visando uma excelente relação entre qualidade com produtividade.

\section{PROCEDIMENTO EXPERIMENTAL}

O produto estudado foi uma roda de liga de alumínio de motocicleta da série A356, fundida por gravidade na indústria de fabricação da motocicleta. A Tabela 1 apresenta a composição química em percentual em peso da liga A356. A liga sofreu modificação com estrôncio.

Tabela 1. Composição química da liga utilizada neste trabalho (\% em peso)

\begin{tabular}{ccccccccccc}
\hline Alloy & $\mathrm{Si}$ & $\mathrm{Cu}$ & $\mathrm{Fe}$ & $\mathrm{Mg}$ & $\mathrm{Zn}$ & $\mathrm{Mn}$ & $\mathrm{Ti}$ & $\mathrm{Ni}, \mathrm{Pb}$ and $\mathrm{Sn}$ & $\mathrm{Sr}$ & $\mathrm{Al}$ \\
\hline A-356 & 6.788 & 0.019 & 0.144 & 0.321 & 0.012 & 0.009 & 0.0132 & 0.000 & 0.011 & bal.
\end{tabular}

Fonte: Fabricante da motocicleta

O tratamento térmico T6, aplicado na própria indústria de fabricação da motocicleta, foi executado diretamente na roda em estudo, e o os tratamentos térmicos de solubilização e envelhecimento artificial foram realizados à temperaturas de $540^{\circ} \mathrm{C}$ e $156^{\circ} \mathrm{C}$ com duração de cinco (5) hora e duas (2) horas, respectivamente. O tempo do tratamento de solubilização foi contado a partir do instante em que o forno alcançou a temperatura de $540{ }^{\circ} \mathrm{C}$.

Após tratamento de solubilização as amostras foram resfriadas em água a $65{ }^{\circ} \mathrm{C}$, sem agitação, ficando nesta temperatura por 50 segundos e imediatamente reaquecida a $155{ }^{\circ} \mathrm{C}$ para envelhecimento artificial. Após envelhecimento as peças foram arrefecidas ao ar ambiente. 
Os tratamentos térmicos foram realizados em fornos verticais a gás, fabricados sob medida para a produção em larga escala (fabricante: Juku Furnance), que permitiu manter a temperatura previamente definida. As amostras foram colocadas quando as temperaturas dos fornos se encontravam a $540^{\circ} \mathrm{C}$ e $156^{\circ} \mathrm{C}$ para solubilização e envelhecimento, respectivamente.

A Figura 2 apresenta um registro fotográfico da roda estudada neste trabalho, mostrando as vistas de corte, realizado no aro e no raio para medição de dureza e retirada dos corpos de provas para revelação e análise da microestrutura.

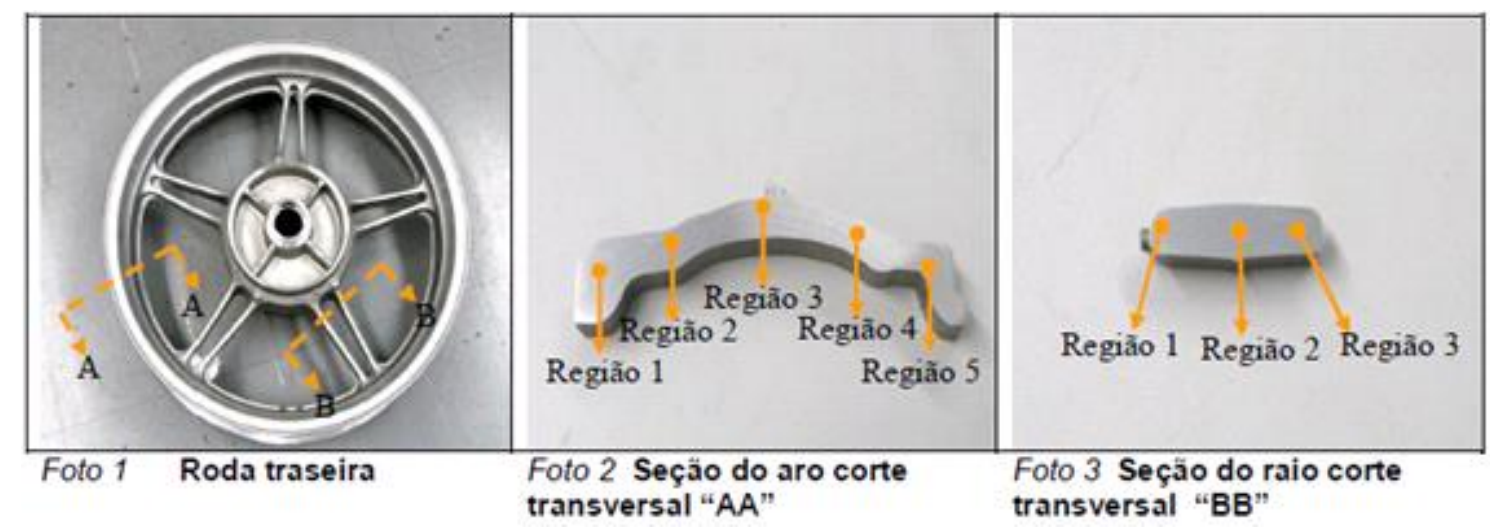

Figura 2. Registro fotográfico da roda traseira da motocicleta, mostrando as regiões analisadas, conforme determinação do fabricante. (Fonte: fornecido pelo fabricante da motocicleta).

Os ensaios de dureza foram realizados no durômetro Wilson-Rockwell - Series B2000, seguindo especificações internas do fabricante da motocicleta, em conformidade à norma ASTM E 18. $O$ indentador usado foi uma esfera de aço com 1,6 mm de diâmetro e a força aplicada de 1000 $\mathrm{N}$ durante 10s. Para cada região (Figura 2) foram realizadas 10 medidas, sendo os resultados apresentados como os valores de mínimo e máximo das respectivas medições, assim como valor médio correspondente.

Técnicas tradicionais de metalografia foram aplicadas, as quais compreendem corte, embutimento, lixamento, polimento, preparação e ataque do reagente químico. A revelação das microestruturas ocorreu mediante imersão das amostras em uma solução aquosa de $5 \%$ de Hidróxido de Sódio $(5 \% \mathrm{NaOH})$ por um tempo de 5 segundos. Em seguida, foram realizadas análises microscópicas para caracterização, revelação e quantificação das microestruturas, com auxílio do sistema de processamento de imagens Olympus, modelo UC30, acoplado ao software de captura de imagem Analise Sys. Toda essa etapa foi realizada no laboratório de caracterização do curso de Engenharia de Materiais do Instituto Federal de Educação Ciência e Tecnologia do Pará - Campus Belém. A quantificação da microestrutura se deu pela medição dos espaçamentos dendríticos secundários $\left(\lambda_{2}\right)$, conforme metodologia tradicionalmente utilizada na literatura, detalha da por Rocha et al (2003). Foram realizadas 20 medidas por corpo de prova, sendo a média dos valores apresentada como resultado.

\section{RESULTADOS E DISCUSSÕES}

As Figuras 3 e 4, apresentam, respectivamente, para o aro (região 5, seção AA, Figura 2) e o raio (região 3 , seção $B B$, Figura 2 ), microestruturas típicas de solidificação, caracterizadas antes 
dos tratamentos térmicos de solubilização e envelhecimento. Observa-se, em ambos os casos, uma microestrutra tipicamente dendrítica, constituída de uma fase $\alpha$ rica em alumínio (Al- $\alpha$ ) com eutético interdrítico, cotendo partículas de Si em forma de lamelas, ligeiramente arrendondadas nas extermidades, devido a modificação do eutético Si causada pelo estrôncio ( $\mathrm{Sr}$ ), e o intermetálico $\mathrm{Mg}_{2} \mathrm{Si}$ (siliceto de magnésio). Na Figura 4b, identifica-se a apresença do siliceto de magnésio em regiões próximas ao eutético, apresentando a morfologia típica de "Escrita Chinesa". A Escrita Chinesa da fase $\mathrm{Mg}_{2} \mathrm{Si}$ foi observada por Garat e Scallet (1978) e mais recentemente por Furlan (2008) e por Moreira (2011).

A morfologia do silício eutético revela-se fina e fibrosa, tal como esperado, pois a liga é modificada com a adição de estrôncio. Observação semelhante foi realizada por Oliveira (2012) para a liga Al-Si-Mg-Mn e Furlan (2008) para a liga A356, ambas modificadas com estrôncio. Observa-se também uma microestrutura dendrítica com tamanho dos espaçamentos dendrítcio secundários $\left(\lambda_{2}\right)$ iguais a $29,5 \mu \mathrm{m}$ e $30,8 \mu \mathrm{m}$ para o aro e o raio da roda, respectivamente. Esta microestrutura é típica de solidificação em molde pernamente, refrigerado à água.

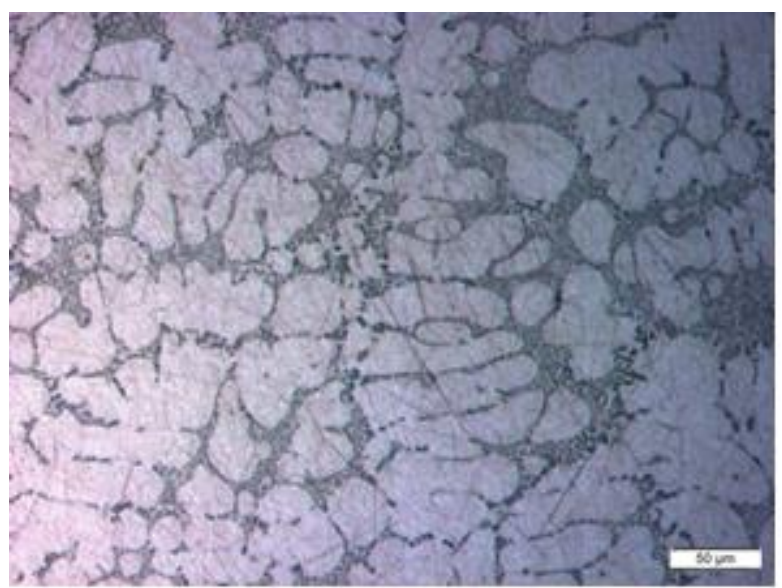

(a)

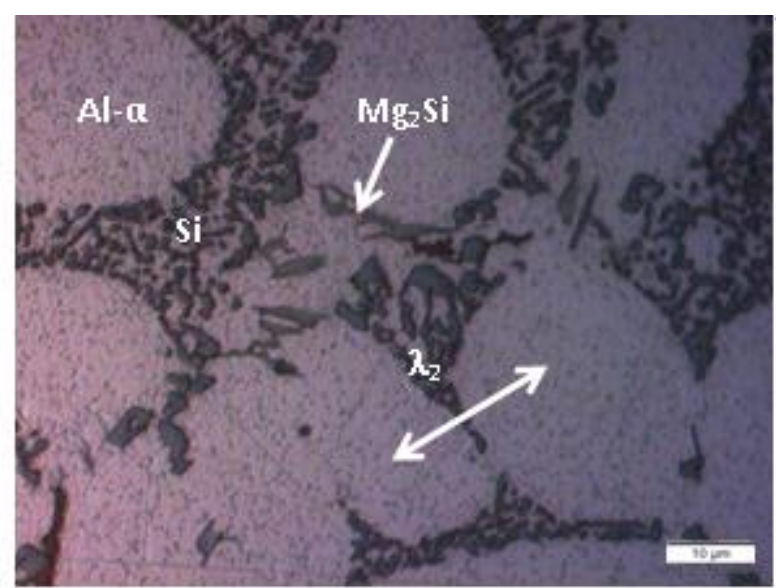

(b)

Figura 3. Microestruturas do Aro da roda, antes do tratamento T6, tipicamente dendrítica, apresentando prtículas de Si lamelar e intermetálicos $M_{2} S i$ interdendríticos, tipo escrita chinesa: (a) aumento 200x e (b) aumento 1000x $\left(\lambda_{2}=29,5 \mu \mathrm{m}\right)$

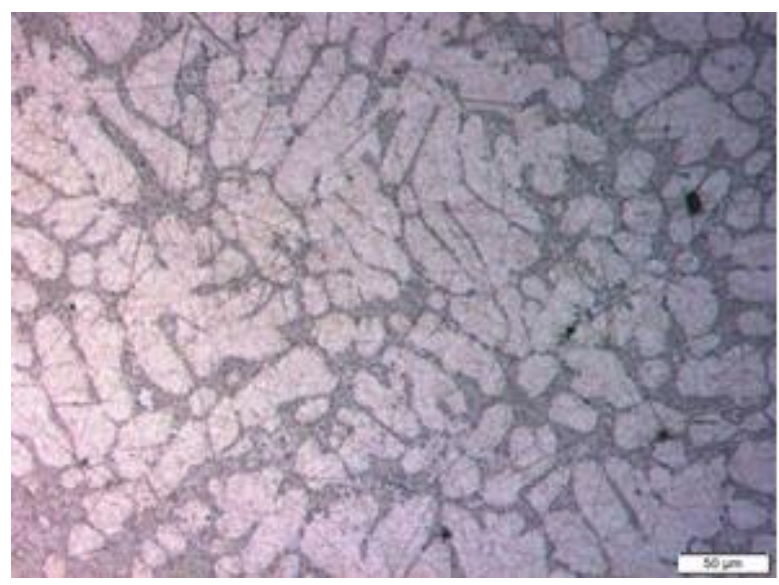

(a)

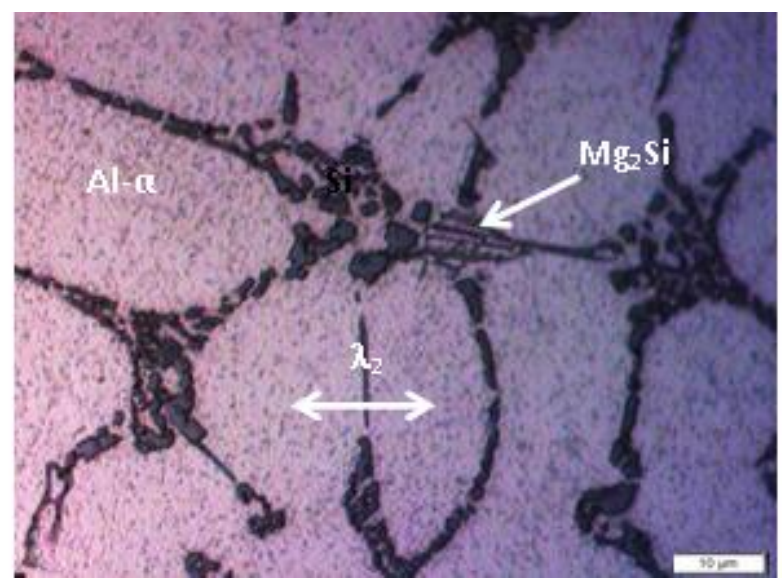

(b)

Figura 4. Microestruturas do raio da roda, antes do tratamento T6, tipicamente dendrítica, apresentando prtículas de Si lamelar e intermetálicos $\mathrm{M}_{2} \mathrm{Si}$ interdendríticos, tipo escrita chinesa: (a) aumento 200x e (b) aumento 1000x.

$\left(\lambda_{2}=30,8 \mu \mathrm{m}\right)$. 
As Figuras 5 e 6, mostram, respectivamente, para o aro (região 5, seção AA, Figura 2) e o raio (região 3, seção BB, Figura 2 ) da roda analisada, microestruturas dendríticas, caracterizadas após os tratamentos térmicos de solubilização e envelhecimento. A microestrutura da liga é afetada com o tratamento térmico T6, onde se observa o coalescimento, esferoidização e crescimento das partículas de silício eutético, resultando num formato mais arredondado e o maior tamanho das partículas na microestrutura quando comparado com o estado bruto de solidificação. Inter-relacinando as observações verificadas nas Figuras 3 e 4 com às da Figuras 5 e 6, avalia-se que os espaçamentos dendríticos secudários, quantificados após o tratamento térmico, resultaram nos valores de 30,1 $\mu \mathrm{m}(29,5 \mu \mathrm{m}$ antes de T6) e 28,75 $\mu \mathrm{m}(30,8 \mu \mathrm{m}$ antes de T6), para o aro e o raio da roda, respectivamente, quasse na mesma ordem de grandeza dos encontrados para as estrututuras brutas de fusão. Nota-se, portanto, que o tratamento T6, aplicado neste trabalho, pouco afetou quantitativamente a microestrutura dendrítica rica em alumínio (fase Al- $\alpha$ ).

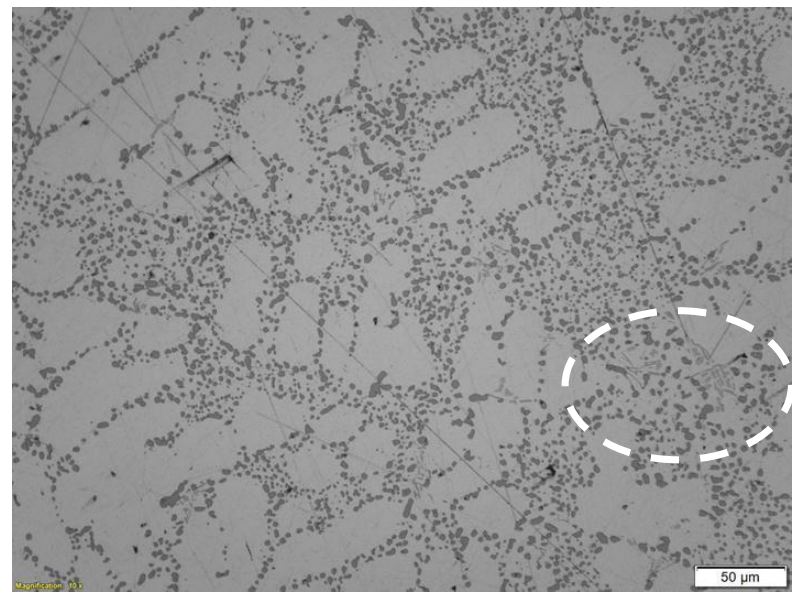

(a)

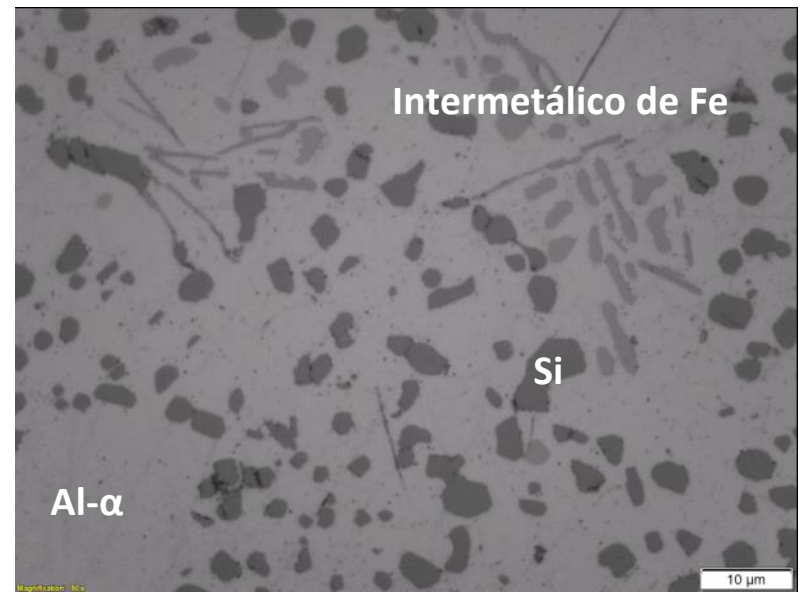

(b)

Figura 5. Microestruturas do aro da roda, tipicamente dendrítica, após tratamento T6, apresentando prtículas de Si esferoidizida e e Fe interdendríticos: (a) aumento 200x e (b) aumento 1000x. $\left(\lambda_{2}=30,1 \mu \mathrm{m}\right)$.

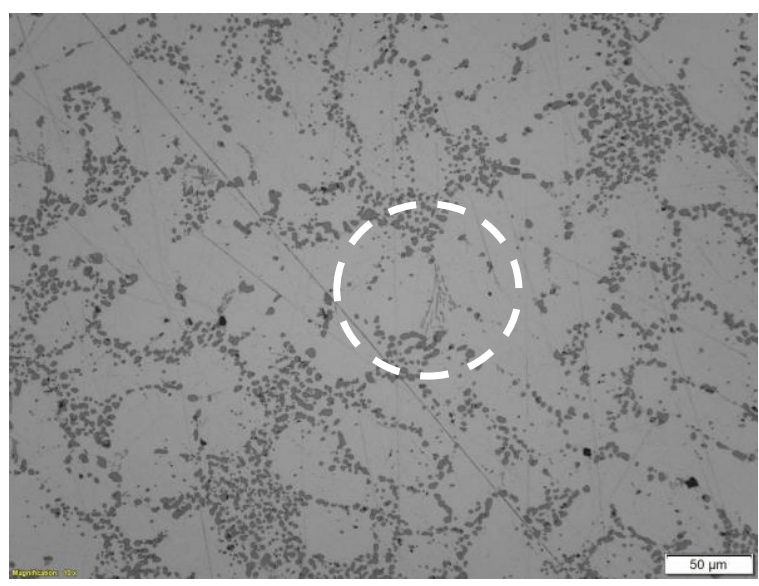

(a)

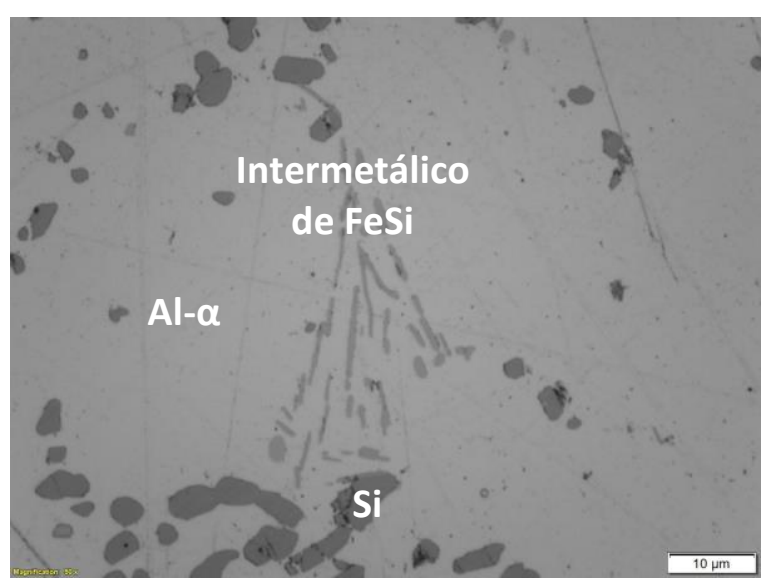

(b)

Figura 6. Microestruturas do raio da roda, tipicamente dendrítica, após tratamento T6, apresentando prtículas de Si esferoidizida e e Fe interdendríticos: (a) aumento 200x e (b) aumento 1000x. ( $\left.\lambda_{2}=28,85 \mu \mathrm{m}\right)$. 
É também possível observar, para ambas microestruturas apresentadas pelas Figuras 5 e 6 , a presença de intermetálicos de $\mathrm{Fe}$, em sua grande maioria em forma de placas grosseiras (coloração cinza claro) entre a fase eutética, com arrendodamento nas extremidades, distribuídos entre as particulas de Si esferoidizadas, e outras de forma arrendodada.

Os resultados de dureza Rocwell B (HRB), medidos nas regiões representadas na Figura 2, estão mostrados nas Tabelas 2 e 3 . Observa-se que as médias gerais, entre os valores obtidos, para o aro e o raio da roda, foram de 46,7 e 47,7 HRB, respectivamente, muito próximo do valor máximo aceitável, estabelecido pelo fabricante (50 HRB). Esses valores podem ser atribuídos à precipitação do intermetálico $\mathrm{Mg}_{2} \mathrm{Si}$ durante o tratamento T6, após envelhecimento artificial.

Tabela 2. Resultados da dureza para as regiões estabelecidas no aro, após tratamento T6.

\begin{tabular}{|c|c|c|c|c|c|}
\hline $\begin{array}{c}\text { Propriedade } \\
\text { Mecânica }\end{array}$ & Região & $\begin{array}{c}\text { Especificado } \\
\text { (HRB) }\end{array}$ & Encontrado (HRB) & $\begin{array}{r}\text { Média } \\
\text { (HRB) }\end{array}$ & $\begin{array}{c}\text { Média Geral } \\
\text { (HRB) }\end{array}$ \\
\hline \multirow{5}{*}{ Dureza } & 1 & \multirow{5}{*}{$30 \sim 50$} & $46 \sim 47,3$ & 46,8 & \multirow{5}{*}{$\begin{array}{c}46,7 \text { (Desvio } \\
\text { padrão } S= \\
0,86)\end{array}$} \\
\hline & 2 & & $43 \sim 45,2$ & 44,2 & \\
\hline & 3 & & $46 \sim 46,8$ & 46,7 & \\
\hline & 4 & & $47 \sim 47,7$ & 47,4 & \\
\hline & 5 & & $48 \sim 49,1$ & 48,6 & \\
\hline
\end{tabular}

Tabela 3. Resultados da dureza para as regiões estabelecidas no raio, após tratamento T6.

\begin{tabular}{|c|c|c|c|c|c|}
\hline $\begin{array}{l}\text { Propriedade } \\
\text { Mecânica }\end{array}$ & Região & $\begin{array}{c}\text { Especificado } \\
\text { (HRB) }\end{array}$ & Encontrado (HRB) & $\begin{array}{r}\text { Média } \\
\text { (HRB) }\end{array}$ & $\begin{array}{c}\text { Média Geral } \\
\text { (HRB) }\end{array}$ \\
\hline \multirow{3}{*}{ Dureza } & 1 & \multirow{3}{*}{$30 \sim 50$} & $47 \sim 47,8$ & 47,6 & \multirow{3}{*}{$\begin{array}{c}47,7 \text { (Desvio } \\
\text { padrão S = } \\
0,86)\end{array}$} \\
\hline & 2 & & $47 \sim 48,1$ & 47,7 & \\
\hline & 3 & & $47 \sim 48,2$ & 47,9 & \\
\hline
\end{tabular}

\section{CONCLUSÕES}

A microestrutura da liga Al-7Si-0,3Mg no estado bruto de fusão é composta por uma fase dendrítica de alumínio primário (Al- $\alpha$ ) e pela fase eutética ( $\mathrm{Si}+\mathrm{Mg}_{2} \mathrm{Si}$ em forma de Escrita Chinesa), onde se observa partículas de silício eutético em formatos fino e fibroso, resultantes da modificação causada pelo estrôncio. A microestrutura dendrítica refinada com $\lambda_{2}$ iguais a $29,5 \mu \mathrm{m}$ e 30,8 $\mu \mathrm{m}$ para o aro e o raio da roda, respectivamente, é típica de estrutura bruta de fusão, obtida para moldes permanentes e refrigerados. Após o tramento térmico T6, verificou-se na solubilização, como esperado, alteração na microestrutura microssegregada, ocorrendo o coalescimento e esferoidização das partículas de silício, mas sem afetar o tamanho da micorestrutura dendendrítica rica em fase Al- $\alpha$. Foi possível também observar, após o tratamento térmico de envelhecimento, a presença de intermetálicos, predominantemente os do tipo de $\mathrm{Fe}$ responsável, juntamente com os intermetálicos $\mathrm{Mg}_{2} \mathrm{Si}$ precipitados, pela alta dureza encontrada nas regiões analisadas. 


\section{AGRADECIMENTOS}

Ao Instituto Federal de Educação, Ciência e Tecnologia do Pará (IFPA), ao ITEGAM/AM e ao Programa de Pós-Graduação de Engenharia Industrial (PPGEI) da Universidade Federal do Pará, pelo apoio de infraestrutura e financeiro, concedidos para a realização deste trabalho.

\section{REFERÊNCIAS BIBLIOGRÁFICAS}

1. CHAUDHURY, S. K., WANG, L., APELIAN, D. Fluidized Bed Reactor Heat Treatment of A356 Alloy: Microstructure Analysis and Mechanical Properties. Transactions of the American Foundry Society, p.289- 304, 2004.

2. CLOSSET, B., GRUZLESKI , J. E. Structure and Properties of Hypoeutectic Al-Si-Mg Alloys Modified with Pure Strontium. Metallurgical Transactions A, v. 13A, p. 945-951, 1982.

3. FURLAN, T. S. Influência do teor de estrôncio na modificação da liga A356. São Paulo, 20018. Dissertação de Mestrado - Escola Politécnica da Universidade de São Paulo, São Paulo, Brasil, 2008.

4. GARCIA, A. Solidificação Fundamentos e Aplicações. UNICAMP-SP, 2007.

5. GRUZLESKI, J.E., The Treatment of Liquid Aluminum-Silicon Alloys: Des Plaines, Ill. : American Foundrymen's Society. p.25-91, 1990.

6. KIM, H.Y., HAN, S.W., LEE, H.M. The Influence of $\mathrm{Mn}$ and $\mathrm{Cr}$ on the Tensile Properties of A3560.20Fe Alloy. Materials Letters, v. 60(15), p. 1880-1883, 2006.

7. LIMA, N. A. G. Tratamento térmico de envelhecimento da liga de fundição AlSi10Mg(Fe). Porto, 2012. Dissertação de Mestrado - Mestrado Integrado em Engenharia Metalúrgica e MateriaisFaculdade de Engenharia da Universidade do Porto, Portugal, 2012.

8. MANENTE, A., TOMELLI, G. Optimizing the Heat Treatment Process of Cast Aluminium Alloys, Recent Trends in Processing and Degradation of Aluminium Alloys, Prof. Zaki Ahmad (Ed.), ISBN: 978-953- 307-734-5, InTech, Available from: http://www.intechopen.com/books/recent-trends-in-processing-anddegradation-ofaluminium-alloys/optimizing-the-heat-treatment-process-of-cast-aluminium-AlloysProcess of Cast Aluminium Alloys, 2011.

9. Metals Handbook, v. 15, 9th ed., American Society for Metals, Metals Park, OH, 1988.

10. MOREIRA, P. S. Efeito da taxa de resfriamento e dos tratamentos térmicos sobre as propriedades mecânicas da liga Al-Si-Mg (A356.0). Minas Gerais, 2011. Dissertação de Mestrado - Engenharia de Materiais da Rede Temática em Engenharia de Materiais-REDEMAT, Universidade Federal de Outro Preto, Minas Gerais, Brasil, 2011.

11. OLIVEIRA, G. R. V. Tratamento térmico de uma liga Al-Si-Mg-Mn. Dissertação de Mestrado. Porto, 2012. Dissertação de Mestrado - Mestrado Integrado em Engenharia Metalúrgica e Materiais, Faculdade de Engenharia da Universidade do Porto, Portugal, 2012.

12. OUELLET, P., SAMUEL, F. H. Effect of Mg on the ageing behaviour of Al-Si-Cu 319 type aluminium casting alloys. Journal of Materials Science, v. 34, p. 4671-4697, 1999.

13. OZBAKIR, E. Development of Aluminum Alloys for Diesel-Engine Applications. Thesis. Department of Mining and Materials Engineering McGill University, Montréal, Québec, 
Canada, 2008.

14. ROCHA, O. L., SIQUEIRA, C. A., GARCIA, A. Heat flow parameters dendrite spacings during unsteady state solidification of $\mathrm{Sn}-\mathrm{Pb}$ and $\mathrm{Al}-\mathrm{Cu}$ alloys. Metallurgical and Materials Transactions A, v.34A, p.995-1006, 2003.

15. SHIVKUMAR, S., KELLER, C.; APELIAN D. Aging behavior in cast Al-Si-Mg alloys. AFS Transactions, v. .98, p. 905-911, 1990a.

16. SHIVKUMAR, S., RICCI JR, S.; APELIAN, D. Influence of solution and simplified supersaturation treatment on tensile properties of A356 alloy. AFS Transactions, v. 98, p. 913-922, 1990b.

17. SHIVKUMAR, S., RICCI, S., KELLER, C. APELIAN, D. Effect of solution treatment parameters on tensile properties of cast aluminum alloys. Journal of Heat Treating, v.8, n.1, p. 63-70, 1990c.

18. Standard Practice for Heat Treatment of Aluminum Alloys, Annual Standard Book of ASTM Standards, B597, v.2, p. 430-441, 1998.

19. TASH. M., SAMUEL, F.H., MUCCIARDI, F., DOTY, H.W. Effect of metallurgical parameters on the hardness and microstructural characterization of as-cast and heat-treated 356 and 319 aluminum alloys. Materials Science and Engineering A, v.443, p. 185-201, 2007.

20. WANG, Q.G., APELIAN, D., LADOS, D.A. Fatigue Behavior of A356/357 Aluminum Cast Alloys. Part II - Effect of Microstructural Constituents. Journal of Light Metals,.v. 1(1), p. 85-97, 2001.

21. ZHANG D. Precipitation of Excess Silicon During Heat Treatment of Cast Al-7wt.\%Si-0.4wt.\%Mg Alloy. Materials Science Forum, 1996. V. 217-222, p. 771-776, 1996.

22. ZHEN, L., FEI, W. D., KANG, S. B., KIM, H. W. Precipitation behaviour of Al-Mg-Si alloys with high silicon content. Journal of Materials Science, v.32, p.1895-1902, 1997.

23. EMADI, D., WHITING, L. V., SAHOO, M., SOKOLOWSKI , J. H., BURKE, P., HART, M., CREPEAU, P.N. Optimal heat treatment of A356.2 alloy. Crepeau, P.N. (Eds.), Light Metals, p. 983-989, 2003.

24. Standard Test Methods for Rockwell Hardness of Metallic Materials to ASTM E18-14. STANDARD by ASTM International, 03/01/2014.

25. GARAT M.; SCALLIET; R. A Review of Recent French Casting Alloy Development. AFS Transactions, V. 86, p. 549-562, 178.

26. PEDERSEN, L., ARNBERG, L.The effect of solution heat treatment and quenching rates on mechanical properties and microstructures in AISiMg foundry alloys. Metallurgical and Materials Transactions Av. 32, p. 525-532, 2001. 